\title{
Water permeability of argillite-based ceramic tiles
}

\author{
Yana Lazareva ${ }^{1, *}$, Anton Kotlyar $^{1}$, Marina Orlova $^{1}$, and Kira Lapunova ${ }^{1}$ \\ ${ }^{1}$ Don State Technical University, 1 Gagarin Sq., Rostov-on-Don, 344010, Russia
}

\begin{abstract}
The article presents the results of experiments to determine the interconnection between water impermeability and water absorption of ceramic tiles obtained on the basis of argillite-like clays that are widespread in the Southern Russia. It is shown that with a decrease in water absorption, the permeability of ceramics is normally reduced. It is found out that with $5 \%$ water absorption, a tile can be considered guaranteed waterproof. In this case, the index is independent of the tile thickness. It has been proved that it is possible to reduce the water absorption and increase the bending strength of tiles based on argillite-like clays by finer grinding of raw material or increasing the burning temperature. It is justified that the production of ceramics with high strength and low water absorption makes it possible to produce tiles with a smaller thickness and weight, as well as with lesser probability of biological corrosion.
\end{abstract}

Ceramic tiles all over the world are the most popular and common roofing material in civil engineering. Due to the properties, ceramic tiles have been used in construction for about 4000 years. Tile is a very durable material: even being a hundred years old, it continues to perform its functions. Normally, the service life of the tiles is equal to the service life of the building itself. Roof structures with reinforced roofing system as well as properly executed technology of mounting ceramic tiles made it possible to have used tile roofs for centuries without the use of additional protective materials and repairs. In comparison with other materials, ceramic tile has many advantages: durability and reliability, fire safety and fire resistance and attractive aesthetic properties. It is resistant to ultraviolet radiation, chemically aggressive rains, winds and temperature changes. It has low thermal conductivity and the ability to absorb noise, not accumulating static voltage. In our country, due to some subjective and objective reasons, from the second half of the 20th century ceramic tiles had practically not been produced and, accordingly, had not been used in construction. Interest in ceramic tiles was re-emerged only at the beginning of this century [1-3]. At present, the demand for ceramic tiles is constantly growing. Even despite the economic crisis of 2014, sales growth did not stop. This is confirmed by the introduction of the new state standards for ceramic tiles. Now ceramic tile is positioned as an elite roofing material. This is largely due to its relatively high cost. The square meter of ordinary tile costs 800-1000 rubles, and tiles that are glazed, engobed or with various decorative effects

\footnotetext{
* Corresponding author: yana-cherevkova@yandex.ru
} 
- 2-3 times more expensive. The high cost is due to the fact that almost all ceramic tiles are imported from abroad, which is a serious deterrent of the widespread use. According to our calculations, if ceramic tiles were manufactured in Russia, then the cost could be 2-3 times less.

The main trends in the production and application of ceramic tiles are currently as follows:

- a large number of options for the decoration by glazing, engobing, volumetric coloring, etc., which contributes to greater diversity and assortment range, giving uniqueness and originality to each individual building;

- pursuit of increasing the strength of the burnt ceramic material;

- pursuit of decreasing water absorption of products and, accordingly, water permeability.

Increased burnt ceramic material strength and decreased water absorption allow to reduce thickness of the products and, correspondingly, their weight $[2,4,5]$. This is a general trend for many manufacturers. Achieving high strength and low water absorption is possible only with intense sintering of the ceramic material. The tests carried out by us showed that water absorption of the tiles from leading manufacturers in Europe fluctuates in the range of $2-6 \%$, and the mass of $1 \mathrm{~m} 2$ of roofing is $35-50 \mathrm{~kg}$. Whereas, according to GOST R 56688-2015 State Standard on Technical Specifications for Ceramic Tiles, the mass of $1 \mathrm{~m} 2$ of interlocking or S-shaped tiles in a water-saturated state should not be more than $54 \mathrm{~kg}$, Monk and Nun tiles - not more than $74 \mathrm{~kg}$. Low water absorption makes it possible for some manufacturers to guarantee the frost resistance of tiles up to 1000 cycles of alternating freezing and thawing. Also, the strength of the tiles generally exceeds the indices required by GOST R 56688-2015 State Standard on Technical Specifications for Ceramic Tiles - 6-12 MPa depending on the type of tile.

The organization of manufacturing ceramic tiles with such parameters causes difficulties in our country, primarily due to limited reserves of vitrifying clays capable of giving ceramic material with water absorption of less than $5 \%$ and high strength indexes after burning. Besides, considering tiles shape and burning conditions, a very important indicator is deformations which should be minimal during the burning. Selection of raw materials for obtaining the desired characteristics is not a simple technological task, taking into account economic factors. The research that we conducted in recent years jointly with regional geological organizations has made it possible to reveal new promising raw materials for the production of ceramic tiles - argillites and their varieties [6-8]. These rocks have specific properties and chemical-mineralogical composition. They are characterized by poor water soaking, increased content of potassium oxide and aluminum in comparison with loams, presence of mica and hydromica of various morphological types, increased bending strength of the burned material, a clear dependence of the products properties on the burning temperature and the degree of grinding of raw material $[9,10]$. In Figures 1 and 2, the dependences of water absorption and bending strength for argillites from the Yuzhno-Cherevkovskoye Argillite Deposit. 


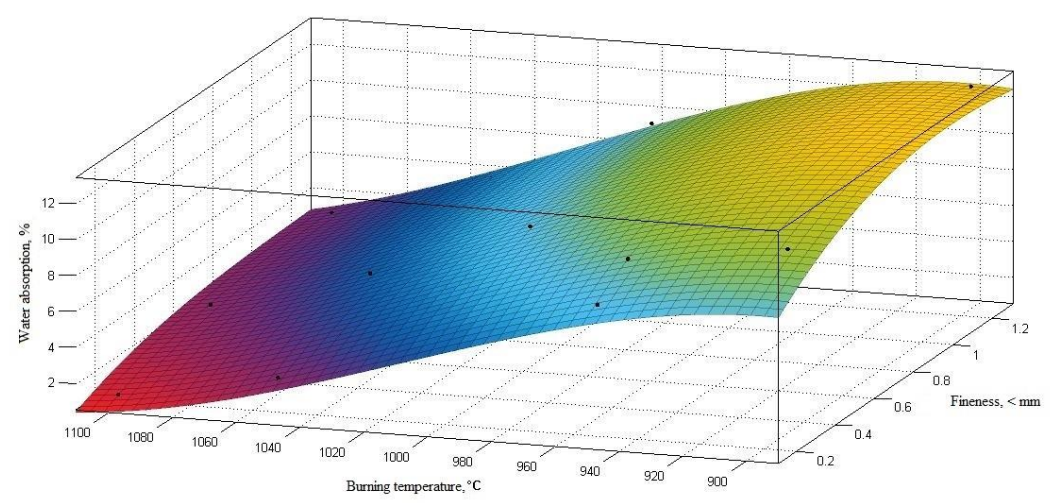

Fig. 1. Influence of burning temperature and degree of grinding on water absorption

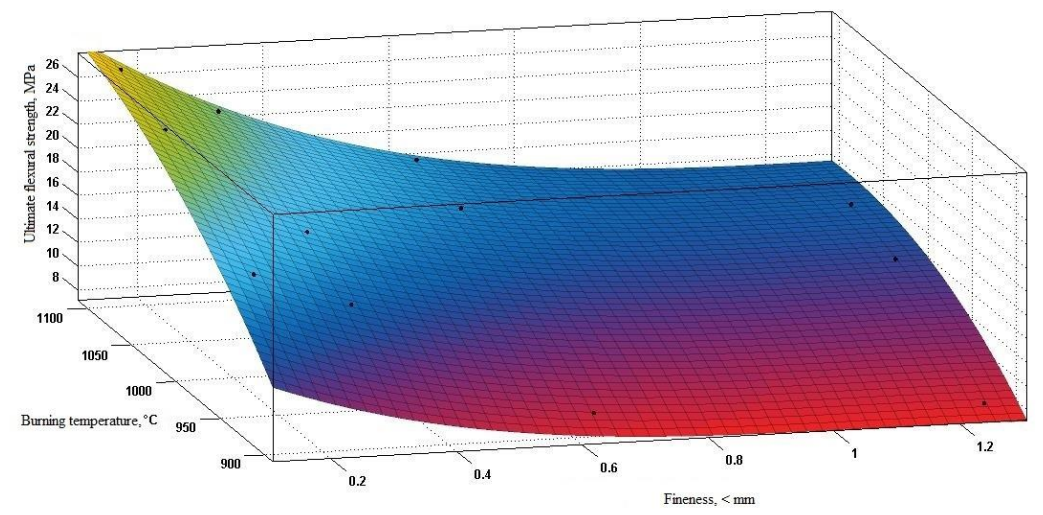

Fig. 2. Influence of burning temperature and degree of grinding on bending strength

As can be seen, the burned material based on argillites has a high bending strength, which makes it possible to produce tiles with a lower thickness and relatively low water absorption. Water absorption rates of less than $6 \%$ are achieved depending on the degree of grinding at buring temperatures of $980-1060{ }^{\circ} \mathrm{C}$. However, GOST R 56688-2015 State Standard on Technical Specifications for Ceramic Tiles does not include requirements for water absorption, but only indicates that the tiles should be waterproof.

Moreover, the method for determining water impermeability has changed. To determine water impermeability, regulatory documents of previous years required a tube with an internal diameter of $25 \mathrm{~mm}$ and a height of $150 \mathrm{~mm}$ to be installed on the sample and filled with water, and if after three hours there were no drops of water on the lower surface of the sample, the tile was considered waterproof. In accordance with GOST R 56688-2015 State Standard, to determine the impermeability, the tile is placed on the supports with the front surface facing upwards and a special detachable frame with dimensions of length and width $10 \mathrm{~mm}$ smaller than the overall dimensions of the sample is placed on it. The gaps between the frame and the edges of the tile, as well as the fixing holes, are sealed, with the bottom surface of the tile being clearly visible. The frame is filled with water so that the water level is at a distance of not less than $10 \mathrm{~mm}$ above the highest relief of the tile and kept for 4 hours. During the test, the initial level of water in the frame is maintained all the time. 
After 4 hours, the bottom surface of the tiles is inspected, and the presence or absence of drops on it is determined.

When selecting raw materials and technological parameters for the production of tiles, it is not possible to determine water impermeability on standard samples. It is more rational to study water absorption of the samples reaching certain values, and then to determine water impermeability. In general terms, from the general technology of ceramics it is clear that the lower the water absorption, the lower the water permeability. However, water impermeability depends on many factors - total porosity, pore sizes and shapes, thickness of samples, etc. We conducted a series of experiments to establish the interdependence between water absorption and water impermeability of argillite-based samples obtained at various technological parameters. The tests were conducted in two ways, which showed similar results on samples with dimensions of $150 \times 150 \times 18 \mathrm{~mm}$.

The conducted experiments have yielded interesting results that we have tried to organize in Table 1.

Table 1. Results of experiments

\begin{tabular}{|c|c|c|c|c|}
\hline \multirow[t]{2}{*}{ No } & \multirow{2}{*}{$\begin{array}{c}\text { Water } \\
\text { absorption, } \\
\%\end{array}$} & \multicolumn{2}{|c|}{ Sampling parameters } & \multirow[t]{2}{*}{ Nature of impermeability } \\
\hline & & $\begin{array}{l}\text { Degree of } \\
\text { grinding, } \\
\mathrm{mm}\end{array}$ & $\begin{array}{c}\text { Burning } \\
\text { temperature, } \\
{ }^{\circ} \mathrm{C}\end{array}$ & \\
\hline 1 & $>10$ & $\begin{array}{c}0-1,25 \\
0-0,63 \\
0-0,315\end{array}$ & $900-950$ & $\begin{array}{l}\text { Large drops appear within } 0.5-1.5 \\
\text { hours after the start of testing }\end{array}$ \\
\hline 2 & $6-10$ & $\begin{array}{r}0-1,25 \\
0-0,63 \\
0-0,315\end{array}$ & $950-1000$ & $\begin{array}{l}\text { Small drops appear within 3-6 hours } \\
\text { after the start of testing }\end{array}$ \\
\hline 3 & $3-6$ & $0-1,25$ & $1050-1100$ & $\begin{array}{l}\text { The sample surface gets wet within } 4 \\
\text { hours, sometimes with a thin film of } \\
\text { moisture }\end{array}$ \\
\hline 4 & $<3$ & $\begin{array}{c}0-1,25 \\
0-0,63 \\
0-0,315 \\
0-0,16 \\
\end{array}$ & $1050-1150$ & $\begin{array}{l}\text { On the the sample surface there is no } \\
\text { moisture, but with water absorption of } \\
2-3 \% \text { it is felt that the sample is wet }\end{array}$ \\
\hline
\end{tabular}

By the nature of impermeability, all samples were conditionally divided into 4 groups:

- with high water permeability - water absorption of more than $10 \%$;

- with medium water permeability - water absorption 6-10\%;

- with low water permeability - water absorption 3-6\%;

- water impermeable - water absorption 0-3\% (Figure 3). 


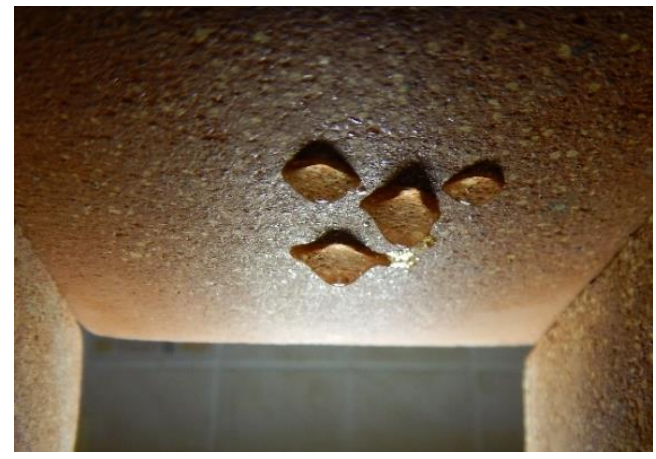

$a$

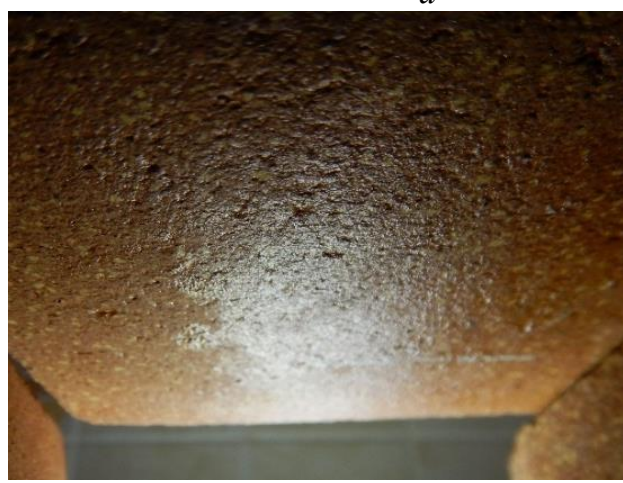

$c$

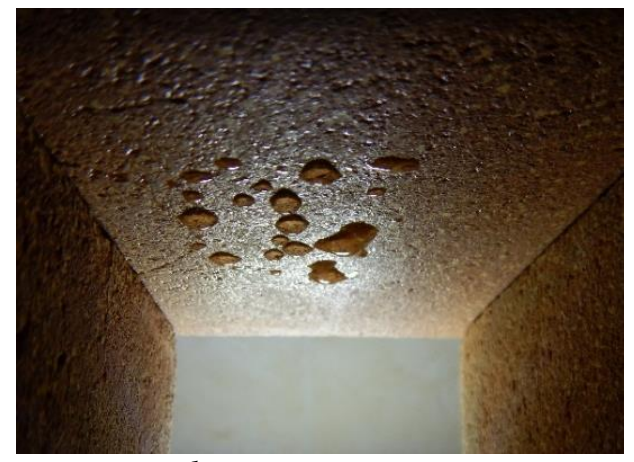

$b$

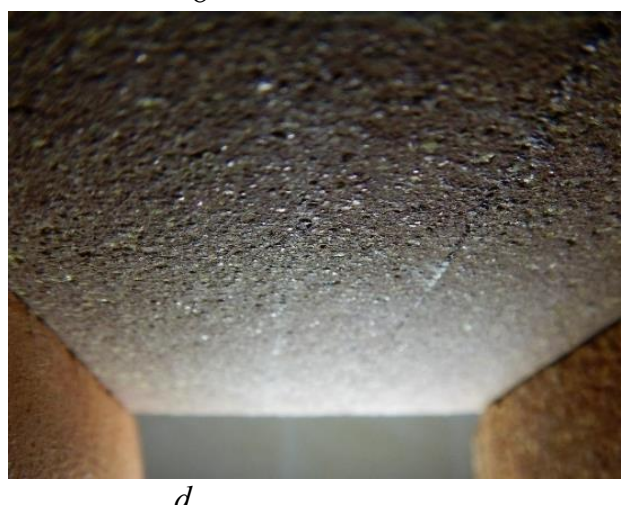

$d$

Fig. 3. Nature of water impermeability: $a$ - with high water permeability; $b$ - with medium water permeability; $c$ - with low water permeability; $d$ - water impermeable

Analysis of the obtained results showed that to achieve guaranteed water impermeability the water absorption of the tiles based on argillite-like clays should not exceed 5\%. Exactly with this water absorption it is possible to build insulated roofs with minimal slopes, the tiles will not be subjected to biological corrosion, will have frost resistance for more than 100 cycles and with water absorption of less than $3 \%$ - even more than 200 cycles. With water absorption of $1-5 \%$, the samples have bending strength of 20 $30 \mathrm{MPa}$, which makes it possible to produce argillite-based tiles that are 1.5-2 times thinner than usual ones. This will reduce the cost price, making it more attractive to a consumer.

\section{References}

1. Terekhov V. A., Stroitel'nye materialy 12, 21 (2002)

2. Kotlyar V. D., Lapunova K.A., Lazareva Ya.V., Usepyan I.M. Stroitel'nye materialy 12, 29 (2015)

3. Salakhov A.M., Tuktarova G. R., Mochalov A.Yu., Salakhova R.A. Stroitel'nye materialy 9, 18 (2007)

4. LazarevaYa.V., Kotlyar V. D., Lapunova K.A., Design. Materials. Technology 3, 78 (2016)

5. Orlova M.E., Lapunova K.A. Materials of the international scientific and practical confer-ence 1, 46 (2018) 
6. Eremenko G.N., Lapunova K.A., Lazareva Y.V. Inzhenernostroitel'nyivestnikPrikaspiya 4, 41 (2015)

7. Kotlyar V. D., Kozlov A.V., Kotlyar A.V., Teryokhina Yu.V. Vestnik MGSU 10, 95 (2014)

8. Talpa B.V., Kotlyar A.V. Stroitel'nye materialy 4, 31 (2015)

9. Kotlyar A.V. Technological properties of claystone-like clays in clinker production. Vestnik Tgsu 2, 164 (2016)

10. A. Mecke, I. Lee, J.R. Baker jr., M.M. Banaszak Holl, B.G. Orr, Eur. Phys. J. E 14, 7 (2004) 